\title{
The Contribution of Forensic Odontology in the Highland Towers Condominium Disaster
}

Alhabshi SF, Nambiar P. The Contribution of Forensic Odontology in the Highland

Towers Condominium Disaster. Annals Dent. Univ. Malaya 1995;2:25-28.

\begin{abstract}
An apartment complex collapsed in Malaysia killing 48 people trapped inside. The dental disaster victim identification team comprising of officers from the Kuala Lumpur General Hospital, Armed Forces and the Dental Faculty, University of Malaya played a very active role in the identification process. Most of the bodies were badly decomposed and some grossly disfigured. Problems were encountered due to inadequate facilities and equipments at the mortuary. Difficulties were also encountered during the procurement and deciphering of information from dental records. Suggestions have been made to improve facilities, expertise and also to create awareness amongst dentists to ensure proper recording of their patients' dental status.
\end{abstract}

\begin{tabular}{|l|}
\hline *Sharifah F. Alhabshi \\
*"Phrabhakaran Nambiar \\
* Senior Dental Consultant \\
and Head of Dental Department \\
Kuala Lumpur General Hospital \\
Kuala Lumpur \\
* Lecturer, Dean's Office \\
Faculty of Dentistry \\
University of Malaya \\
Kuala Lumpur \\
\hline
\end{tabular}

Key Words: Forensic Odontology, disaster, identification, age determination.

\section{INTRODUCTION}

In recent years there were numerous disasters due to natural causes such as earthquakes, cyclones, floods, fires and others due to vehicular accidents and explosives at different parts of the world. Many of these disasters claimed numerous lives and have caused great damage to property and the enviroment. On December 11th, 1993 a different kind of disaster occurred at Ulu Kelang, Selangor, Malaysia. A 12 storey apartment complex built on a hill slope - Block A of Highland Towers collapsed entombing everyone inside. Although the building was believed to have been constructed on a stable foundation, authorities have great diffficulty in determining the actual cause for the crash. Others concede that it was due to land slides occuring in the neighboring area causing water to seep and weaken the foundation.

Within the first hour of the collapse a Japanese housewife, an Indonesian maid and her eighteen month old toddler were rescued. However, the Japanese lady died subsequently at the Kuala Lumpur General Hospital from massive internal injuires. The Malaysian emergency workers comprising of firemen, policemen and defence personnel were joined by rescue teams from Singapore, Japan and France. They arrived with very sophisticated equipments and were assisted with trained sniffer - tracker dogs. They were cautious not to be very aggressive while carrying out their operations for the fear of endangering any surviving victims. Unfortunately, no rescue was made after one week of searching which prompted the disaster management team to tear down the slabs of the building with heavy machinery. Emergency workers started removing bodies on 18th December and this work stretched for the next 6 days. Bodies were then brought to the Kuala Lumpur General Hospital mortuary for postmortem. Two large refrigerated freight containers were borrowed from a shipping agency to complement the mortuary space. Bodies were recovered at different stages of decomposition - some badly mutilated and fragmented while others were actually skeletonised.

The disaster victim identification (DVI) team that was quickly assembled was headed by a senior pathologist of the hospital. It comprised of forensic pathologists, dentists and also a geneticist to help in the identification process. A forensic pathologist was specifically assigned to record and catalogue the identifying information of each victim. The dental DVI team comprised of ten officers. They were from the Dental Department of Kuala Lumpur General Hospital, the Malaysian Armed Forces and the Dental Faculty, University of Malaya. The aim of this article is to illustrate the importance of dental identification done for the first time in a mass disaster in Malaysia. It also reinforces the need for the inclusion of dental experts for confirming or supporting any identification of unknown deceased persons in the future.

\section{IMPORTANCE OF VICTIM IDENTIFICATION}

The death of a Malaysian citizen is officially certified by the issue of a death certificate. A death certificate is necessary to solve many legal matters such as inheritance and succession to property, the collection of insurance policies and pensions, settlement of business matters and also the remarriage of the remaining spouse. Positive identification of victims following an unprecedented accident is imperative to bring to an end the distress on family members, relatives and friends. Furthermore, additional relief may be afforded to a family who learns that an unknown body is not the remains of a missing relative (1). 
Visual recognition represents the most frequent method of identification. Generally the body must be well preserved with intact facial features. Many victims of this disaster could not be identified visually due to the extensive trauma and advanced decomposition. In these conditions, it was deemed advisable not to invite relatives and friends to provide any visual identification. Their judgement in recognizing anybody would be questionable because of the emotional stress that they were experiencing.

Personal effects such as clothing, identity cards, jewellery, prescription spectacles and keys provided some favourable leads in the identification process. However, this is not scientifically reliable as they can be switched with criminal intent or could have been borrowed. The use of fingerprints was limited because of the decomposed nature of the bodies. The pathologists on their part worked to assess age, determine race, sex, stature, disease status as well as the cause and time of death of the deceased. Comparison with the known medical history or prior surgical procedures of a suspected victim may serve to corroborate or exclude an individual. Selected bone tissues were collected by the pathologists and despatched to the geneticist for DNA fingerprinting.

\section{DENTAL IDENTIFICATION}

The procedures of dental identification are credible because the human dentition has very good postmortem preservation - although it undergoes destruction during a person's life. Dental restorations and prostheses are extremely resistant to physical and chemical deterioration and also to the changes to the environment. The unique morphological characteristics of human teeth and dental restorations have great individuality. The availability of routine dental records, especially radiographs provide exacting evidence for comparison. Sometimes the recovery of only a single tooth or jaw fragment maybe unique enough to make a positive identification, provided the antemortem recording has been made. Marking of dentures with names or numbers are recent introduction in the fabrication of dentures. This is followed stringently in 7 states of United States of America (2). Furthermore, it is also important to have a dentist at the site of disaster during body removal and evidence retrieval. This is important as many trained investigators at accident sites tend to overlook dental evidence, which may be crucial for the positive identification of an indiviual.

\section{VICTIMS OF THE DISASTER}

Unlike in an airline crash where a passenger manifest is quickly made available, the Highland Towers disaster management team was unsure of the number of people inside the building. Being a Saturday a afternoon, many had not returned home thus escaping the fatal accident. The police recorded that 48 individuals lost their lives in this mishap.
Table 1 The nationality and ethnicity of the victims of the condominium disaster.

\begin{tabular}{|l|l|}
\hline Nationality & No $\quad$ Ethnicity \\
\hline Malaysians & $38 \quad$ (Chinese - 22, Malays - 10, Indians - 6) \\
\hline Indonesians & 3 \\
\hline Koreans & 2 \\
\hline Britisher & 1 \\
\hline Indians & 2 \\
\hline Filipino & 1 \\
\hline Japanese & 1 (died at the hospital) \\
\hline
\end{tabular}

The above list sufficiently shows the diversity of ethnic, racial, cultural, national and religious affiliation of those who perished (3). This posed a special problem as all bodies had to be identified positively and retumed to their respective relatives for burial or cremation rites in accordance to their own customary traditions.

\section{DENTAL INVESTIGATION AND INTERPRETATION PROCEDURES IN THIS DISASTER}

A total of forty six bodies were examined by the dental identification team. This did not include the victim who was hospitalized before dying. Another did not have any skull bones for examination. Forty bodies had relatively intact maxilla and mandibular bones while six others had fragmented pieces for examination. Dental status of all these bodies were charted on postmortem odontograms. Gaining access for dental examination was relatively easy because most of the bodies were decomposed or skeletonized. Radiological recording of developing teeth of pre-school, school going children and juveniles were taken for estimation of age. As we had access only to intra-oral dental radiographs, both upper and lower jaws of either side were radiographed for age assessment. In cases when all the teeth had completely erupted, radiographs of the third molar was taken to see if the root formation was complete. This was to ensure that the bodies did not belong to any one in the late teens. Age assessment of adults was based on the attritional wear of the teeth. In addition, the level of periodontal attachment and the amount of alveolar resorption were other cumulative factors selected for the same assessment. Difficulties were also faced due to improper lighting and inadequate facilities at the hospital mortuary for serious odontological work.

Numerous problems were also encountered when attempts were made to obtain dental records. A few dental surgeons were reluctant to release the records but provided written statement of the treatment rendered. Several others had to be coaxed and reassured that they would not be implicated for not having adequate recording of their patients. In most cases dental treatment provided by the attending dentist were the only information written on the records. There were also problems in deciphering information due to unfamiliar terminologies and illegible writing. Dental 
records of a few were not traceable because the whole family perished in the disaster. A limited number of them were treated by unqualified dentists who never mantain any form of records. Some foreigners had treatment done in their home countries, while a few Malaysians had their treatment overseas. Lastly, a few families had problems providing information regarding. dental treatment received by their dead relatives because they never had a regular dentist.

Positve identification was possible for sixteen $(34.8 \%)$ bodies because there was adequate antemortem dental records of the missing victim. Radiographs provided excellent confirmatory evidence. Identification of eight other bodies $(17.4 \%)$ were only dentally supported because there were insufficient dental history or only jaw fiagments were retrieved from the site of discovery. These included five edentulous ladies. However none of them had their dentures marked. Accurate age estimation was possible for nine children $(19.6 \%)$, some of whom had mixed dentition. The dental investigators employed the chart prepared by Schour and Massler (4) which demonstrated stages of tooth development and sequence of eruption at yearly interval. In thirteen adult cases $(28.5 \%)$ age estimation from attrition of teeth, periodontal recession and alveolar resorption was made for possible association or exclusion with other findings to help in the identification. This particular method is not considered very reliable, but it is sometimes the only method possible under the given conditions.

Various other information were also gathered from the teeth. These include racial traits, oral hygeine status, smoking habits, socio-economic status and also detailed morphology of the anterior dentition. In selected cases, photographs of supected missing persons expressing his/her teeth were compared with those of the victims. The alignment, shape, size and any malformation or spacing in the anterior teeth were useful for positive identification. Even a video tape recording showing the smiling face of a suspected victim was used for identification. In another case, comparison of a sibling teeth morphology was made. The deceased had a feature called "double-shovel" shaped incisor teeth which corresponded with her sister's dentition. Both the mesial and distal margins of the palatal and labial surfaces of her upper anterior teeth were raised suggesting a familial trait. In extremely difficult situations when antemortem dental records were not available, relatives and family members were sometimes questioned to determine if their deceased relatives had any restorations on their teeth or prosthesis inserted to replace them artificially. Selected teeth were sometimes removed for closer scrutiny and detailed examination under magnifying glass to detect any tooth coloured restorations. Even the dye of an indelible pencil was used to disclose them.

\section{DISCUSSION}

The collapse of the apartment building reinforced the important role of forensic odontology in mass disaster victim identification in Malaysia. For the first time there were requests on television and the newspapers for the dental records of the victims. There was also a greater recognition of the role of dental experts by the pathologists, police officers and other government agencies. Suggestions have been made to improve facilities such as proper lighting, availability of radiological dental machines and provision of adequate dental equipments at the hospital mortuary. There is also a need to have more dental surgeons trained in forensic odontological work by attending post-graduate courses. This is imperative as those trained will become more confident when interpreting dental records and deducing evidence from oral and dental structures.

The dental identification team had a reasonably favourable cooperation from the dental community, although some were hesitant to part with their patient's dental records. In light of this accident, it is hoped that there is a greater awareness amongst practising dentists for the need to mantain adequate dental recording of their patients. They should also become aware that whatever treatment performed can become a potential legal issue later.

The authors also wish to record sincere thanks to Major (Dr.) Tan Peng Hui (Singapore) and Dr. Carl Leung (Hong Kong ) for expressing their readiness to provide their expert assistance. This form of international collaboration is very healthy, especially in the management of mass disasters involving a larger number of victims from several countries. As the number of the deceased were only 48 in this disaster, these numbers were manageable by the dental disaster victim identification team of Malaysia.

\section{ACKNOWLEDGEMENTS}

We wish to put to record that the following were part of the DVI ( Dental ) team during the collapse; Dr. Noraini Nun Nahar, Dr. Criistopher Vincent, Dr. Sharifah Shium Alhabshi Dr. Norinah Mustapha, Dr. Anita Rohini Nesadurai, Dr. Azida Abdul Aziz, Mejar (Dr.) Didar Singh, Mejar (Dr.) Heng Swee Heong.

We also express our sincere thanlcs to Dr. Zaini A Rahman ( Senior Pathologist, Kuala Lurnpur General Hospital), The Forensic Pathology Team, The Royal Malaysia Police Force and the mortuary attendents for having been very helpful in providing the necessary assistance to the dental team. 


\section{REFERENCES}

I. Cottone J A Dental identification. In Cottone J A, Standish S M, eds. Outline of forensic dentistry. 1st edn. Year Book Medical Publishers, 1982, 73-87.

2. McGivney J. Marking of removal dentures. In Averill D C, ed. Manual of forensic odontology. 2nd edn. 'American Society of Forensic Science, 1991; 62-71.

3. Remembering the innocent victims of the condo collapse. The Star (daily) 3/6/1994: 5.

4. Ciapparelli L. The chronology of dental development and age assessment. In Clark D H, ed. Practical Forensic Odontalogy. 1st. edn. Butterworth - Heinmann Ltd, 1992; 29-30. 